\title{
Investigation of Double-layered Pb-Sn Perovskite Absorbers: Formation, Structure, Band Alignment, and Stability
}

Atittaya Naikaew, ${ }^{\mathrm{a}, \mathrm{e}}$ Pisist Kumnorkaew, ${ }^{\mathrm{b}}$ Worawat Wattanathana, ${ }^{\mathrm{c}}$ Khine Zin Swe, ${ }^{\mathrm{a}}$ Pimsuda Pansa-Ngat, ${ }^{a}$ Koth Amratisha, ${ }^{a}$ Hideki Nakajima, ${ }^{\mathrm{d}}$ Ratchadaporn Supruangnet, ${ }^{\mathrm{d}}$ Taweewat Krajangsang, ${ }^{\mathrm{e}}$ Kitiphat Sinthiptharakoon, ${ }^{\mathrm{b}}$ Somboon Sahasithiwat, ${ }^{\mathrm{f}}$ Pongsakorn Kanjanaboos, ${ }^{\mathrm{a}, \mathrm{g},},{ }^{*}$

${ }^{a}$ School of Materials Science and Innovation, Faculty of Science, Mahidol University, Nakhon Pathom 73170, Thailand

${ }^{\mathrm{b}}$ National Nanotechnology Center (NANOTEC), National Science and Technology

Development Agency, Khlong Luang, Pathum Thani 12120, Thailand

${ }^{c}$ Department of Materials Engineering, Faculty of Engineering, Kasetsart University, Bangkok 10900, Thailand

d Synchrotron Light Research Institute, Nakhon Ratchasima 30000, Thailand

${ }^{e}$ National Energy Technology Center (ENTEC), National Science and Technology Development Agency, Khlong Luang, Pathum Thani 12120, Thailand

${ }_{\mathrm{f}}^{\mathrm{f}}$ National Metal and Materials Technology Center (MTEC), National Science and Technology

Development Agency, Khlong Luang, Pathum Thani 12120, Thailand

${ }^{\mathrm{g}}$ Center of Excellence for Innovation in Chemistry (PERCH-CIC), Ministry of Higher

Education, Research and Innovation, Bangkok 10400, Thailand

*pongsakorn.kan@mahidol.edu

\section{Supporting Information}




\section{Materials}

Perovskite precursors were comprised of $\mathrm{PbI}_{2}(99 \%), \mathrm{Pb}(\mathrm{SCN})_{2}(99.5 \%), \mathrm{SnF}_{2}$ (99\%), $\mathrm{DMF}$ (anhydrous, 99.8\%), DMSO (anhydrous, 99.9\%), and 2-propanol (anhydrous, 99.5\%); all were purchased from Sigma Aldrich. MAI (99.99\%), PEAI (99\%), and FAI (99.99\%) were purchased from Great Cell Solar. $\mathrm{SnI}_{2}(99 \%)$ and toluene (anhydrous, 99.85\%) were purchased from Alfa Aesar and ACROS Organics, respectively.

\section{Precursor solution}

$\mathrm{Pb}$-based 2D perovskite materials via Ruddlesden-Popper (R-P) formula could be fabricated for a given $\mathrm{n}$ value, where $\mathrm{n}$ is the number of the octahedral layers sandwiched by the large organic cation following the procedure described in the previous work. ${ }^{1}$ For each $1 \mathrm{ml}$, $\left(\mathrm{FASnI}_{3}\right)_{0.6}\left(\left(\mathrm{PEA}_{2}\right)\left(\mathrm{MA}_{39} \mathrm{~Pb}_{40} \mathrm{I}_{121}\right)\right)_{0.4},(\mathrm{PEA})_{2}(\mathrm{MA})_{\mathrm{n}-1} \mathrm{~Pb}_{\mathrm{n}} \mathrm{X}_{3 \mathrm{n}+1}, \mathrm{n}=40$ or $\mathrm{n} 40$ perovskite was firstly prepared by dissolving $17.8 \mathrm{mg}$ of PEAI powder, $221.6 \mathrm{mg}$ of MAI powder, $659.2 \mathrm{mg}$ of $\mathrm{PbI}_{2}$, and $16.1 \mathrm{mg}$ of $\mathrm{Pb}(\mathrm{SCN})_{2}$ in a 9:1 v/v mixture of $\mathrm{DMF}$ and DMSO. The Sn-based 3D perovskite precursor solution was secondly obtained by mixing $240 \mathrm{mg}$ of FAI, $521 \mathrm{mg}$ of SnI , and $21.9 \mathrm{mg}$ of $\mathrm{SnF}_{2}$ in a mixture of DMF and DMSO at a ratio of $4: 1$. Then, both precursor solutions were stirred at room temperature for 3-6 hours. The 2D/3D mixed $\mathrm{Pb}-\mathrm{Sn}$ perovskite precursor solution was prepared by mixing both precursors at the same volume ratio. Then, stirred until completely dissolved and filtered with PP syringe filter.

\section{Film deposition process}

$50 \mu \mathrm{l}$ 3D/2D mixed $\mathrm{Pb}-\mathrm{Sn}$ perovskite solution was spin-coated onto substrate at 2,000 rpm (with the initial acceleration of $1000 \mathrm{rpm} / \mathrm{s}$ ) for 10 seconds, followed the second speed protocol at 5,000 $\mathrm{rpm}$ (with the initial acceleration of $2500 \mathrm{rpm} / \mathrm{s}$ ) for 10 seconds for 20 seconds. The $400 \mu$ toluene as anti-solvent was then applied at the $15^{\text {th }}$ second from the second step. The film was then annealed at $70{ }^{\circ} \mathrm{C}$ for 30 minutes for the pristine sample. To create the $2 \mathrm{D}$ perovskite buffer layer, $100 \mu \mathrm{l}$ PEAI dissolved in 2-propanol with different concentrations of $0.005,0.015$, and $0.05 \mathrm{M}$ was spun at $6,000 \mathrm{rpm}$ (with the initial acceleration of $6000 \mathrm{rpm} / \mathrm{s}$ ) for $30 \mathrm{~seconds}$ on top the pristine film, and the film was then placed on a hotplate at $100{ }^{\circ} \mathrm{C}$ for 10 minutes. The whole spinning and annealing process were done under a $\mathrm{N}_{2}$-filled glovebox. 


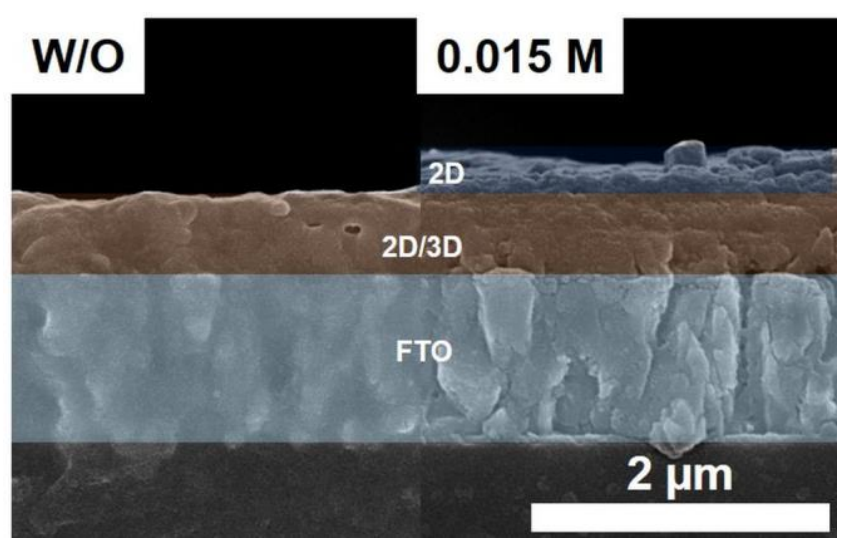

Figure S1. SEM cross-section of 2D/3D mixed $\mathrm{Pb} / \mathrm{Sn}$ perovskite before and after PEAI treatment.
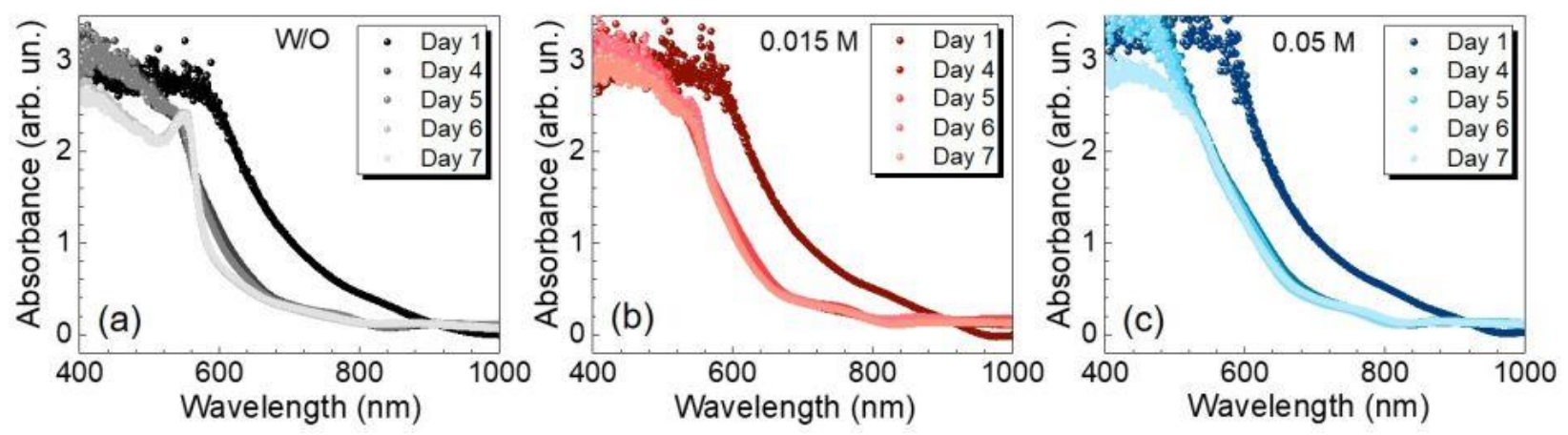

Figure S2. Optical spectra of perovskite films for stability testing over 7 days of (a) without PEAI treatment, (b) with $0.015 \mathrm{M}$, and (c) with 0.05 M PEAI treatment. 


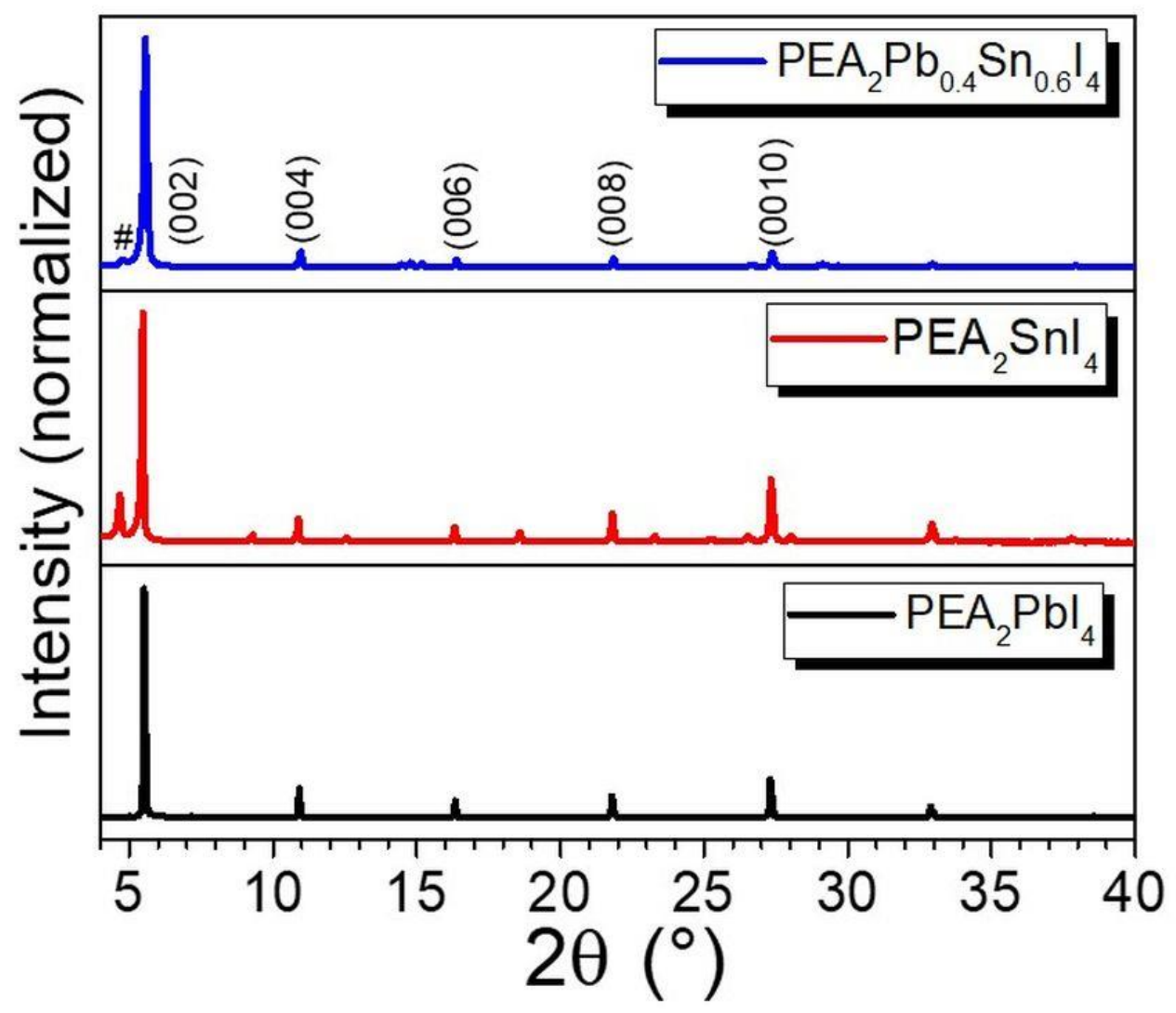

Figure S3. XRD patterns of different 2D perovskite films; $\mathrm{PEA}_{2} \mathrm{PbI}_{4}, \mathrm{PEA}_{2} \mathrm{SnI}_{4}$, and $\mathrm{PEA}_{2} \mathrm{~Pb}_{0.4} \mathrm{Sn}_{0.6} \mathrm{I}_{4}$.
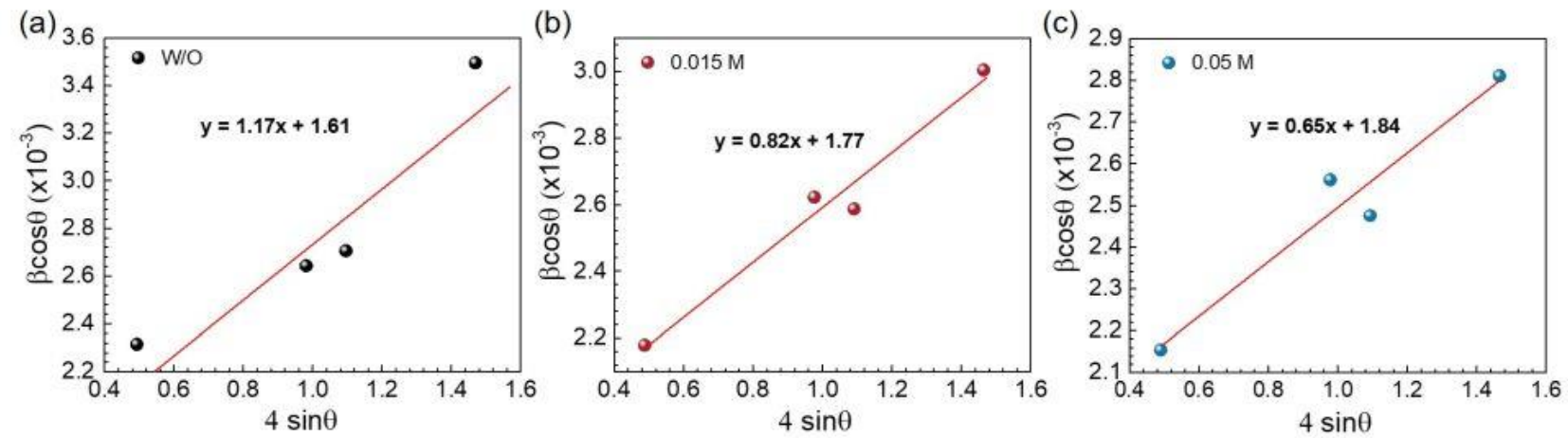

Figure S4. Williamson-Hall plots of 2D/3D mixed $\mathrm{Pb} / \mathrm{Sn}$ perovskite films; (a) without PEAI treatment, (b) with $0.015 \mathrm{M}$, and (c) with $0.05 \mathrm{M}$ PEAI treatment. 


\section{Stability testing}

The summary of stability tests in a variety of conditions of different light, humidity, temperature levels, and the aging time is tabulated in Table S1.

Table S1. The stability tests under a variety of environmental conditions and aging times.

\begin{tabular}{|c|c|c|c|c|}
\hline Sample name & Week 0 & Week 1 & Week 2 & Week 3 \\
\hline 1. $\mathrm{W} / \mathrm{O}$ & $\begin{array}{l}\text { W/O fresh } \\
\text { sample }\end{array}$ & $\begin{array}{l}\text { W/O, } 800 \text { lux } \\
\text { W/O, } 1 \text { Sun } \\
\text { W/O, } 30 \% \text { RH } \\
\text { W/O, 60\% RH } \\
\text { W/O, } 85^{\circ} \mathrm{C} \\
\text { W/O, } 120^{\circ} \mathrm{C}\end{array}$ & $\begin{array}{l}\text { W/O, } 800 \text { lux } \\
\text { W/O, } 1 \text { Sun } \\
\text { W/O, } 30 \% \text { RH } \\
\text { W/O, 60\% RH } \\
\text { W/O, } 85^{\circ} \mathrm{C} \\
\text { W/O, } 120^{\circ} \mathrm{C}\end{array}$ & $\begin{array}{l}\text { W/O, } 800 \text { lux } \\
\text { W/O, } 1 \text { Sun } \\
\text { W/O, } 30 \% \text { RH } \\
\text { W/O, 60\% RH } \\
W / O, 85^{\circ} \mathrm{C} \\
W / O, 120^{\circ} \mathrm{C}\end{array}$ \\
\hline 2. $0.015 \mathrm{M}$ & $\begin{array}{l}0.015 \mathrm{M} \\
\text { fresh sample }\end{array}$ & $\begin{array}{l}0.015 \mathrm{M}, 800 \text { lux } \\
0.015 \mathrm{M}, 1 \text { Sun } \\
0.015 \mathrm{M}, 30 \% \mathrm{RH} \\
0.015 \mathrm{M}, 60 \% \mathrm{RH} \\
0.015 \mathrm{M}, 85^{\circ} \mathrm{C} \\
0.015 \mathrm{M}, 120^{\circ} \mathrm{C}\end{array}$ & $\begin{array}{l}0.015 \mathrm{M}, 800 \text { lux } \\
0.015 \mathrm{M}, 1 \text { Sun } \\
0.015 \mathrm{M}, 30 \% \mathrm{RH} \\
0.015 \mathrm{M}, 60 \% \mathrm{RH} \\
0.015 \mathrm{M}, 85^{\circ} \mathrm{C} \\
0.015 \mathrm{M}, 120^{\circ} \mathrm{C}\end{array}$ & $\begin{array}{l}0.015 \mathrm{M}, 800 \mathrm{lux} \\
0.015 \mathrm{M}, 1 \mathrm{Sun} \\
0.015 \mathrm{M}, 30 \% \mathrm{RH} \\
0.015 \mathrm{M}, 60 \% \mathrm{RH} \\
0.015 \mathrm{M}, 85^{\circ} \mathrm{C} \\
0.015 \mathrm{M}, 120^{\circ} \mathrm{C}\end{array}$ \\
\hline $3.0 .05 \mathrm{M}$ & $\begin{array}{l}0.05 \mathrm{M} \text { fresh } \\
\text { sample }\end{array}$ & $\begin{array}{l}0.05 \mathrm{M}, 800 \text { lux } \\
0.05 \mathrm{M}, 1 \mathrm{Sun} \\
0.05 \mathrm{M}, 30 \% \mathrm{RH} \\
0.05 \mathrm{M}, 60 \% \mathrm{RH} \\
0.05 \mathrm{M}, 85^{\circ} \mathrm{C} \\
0.05 \mathrm{M}, 120^{\circ} \mathrm{C}\end{array}$ & $\begin{array}{l}0.05 \mathrm{M}, 800 \mathrm{lux} \\
0.05 \mathrm{M}, 1 \mathrm{Sun} \\
0.05 \mathrm{M}, 30 \% \mathrm{RH} \\
0.05 \mathrm{M}, 60 \% \mathrm{RH} \\
0.05 \mathrm{M}, 85^{\circ} \mathrm{C} \\
0.05 \mathrm{M}, 120^{\circ} \mathrm{C}\end{array}$ & $\begin{array}{l}0.05 \mathrm{M}, 800 \text { lux } \\
0.05 \mathrm{M}, 1 \mathrm{Sun} \\
0.05 \mathrm{M}, 30 \% \mathrm{RH} \\
0.05 \mathrm{M}, 60 \% \mathrm{RH} \\
0.05 \mathrm{M}, 85^{\circ} \mathrm{C} \\
0.05 \mathrm{M}, 120^{\circ} \mathrm{C}\end{array}$ \\
\hline
\end{tabular}




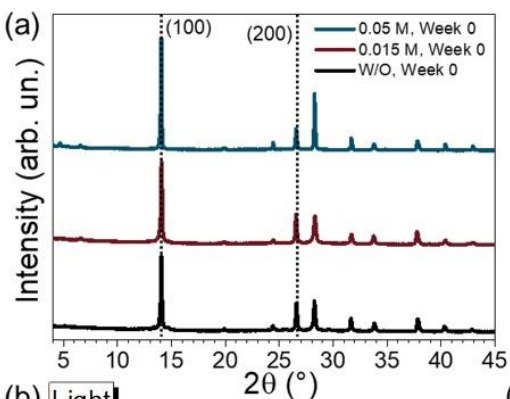

(b) Light

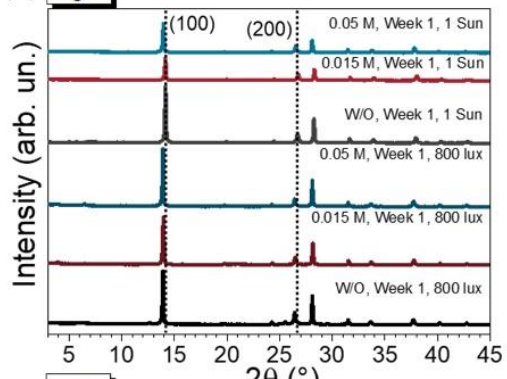

(e) Light

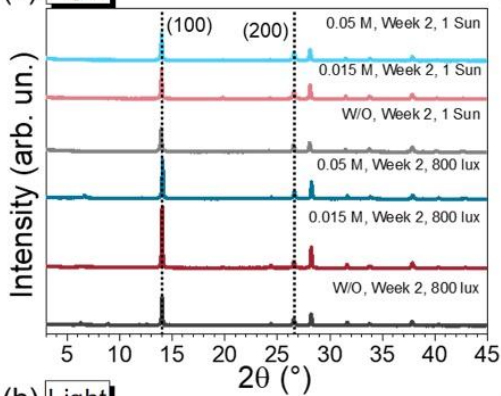

(h) Light

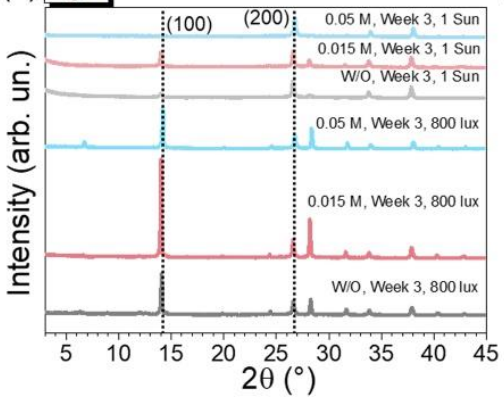

(c) $\mathrm{RH}$

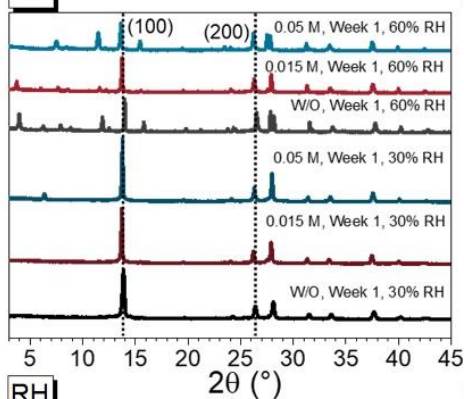

(f) $\mathrm{RH}$

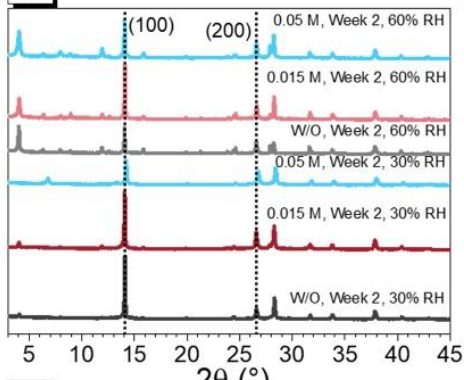

(i) $\mathrm{RH}$

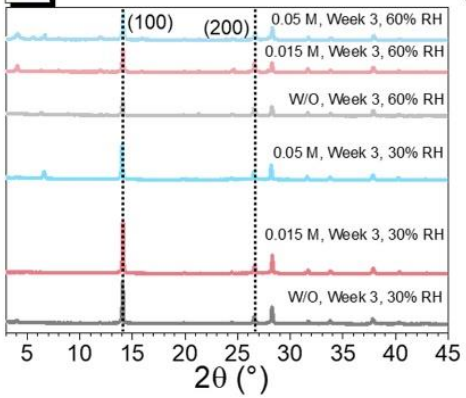

(d) Heat

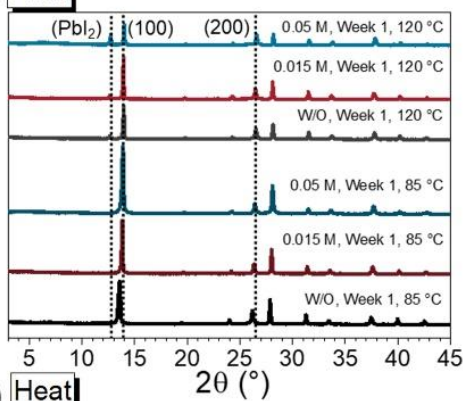

(g) Heat

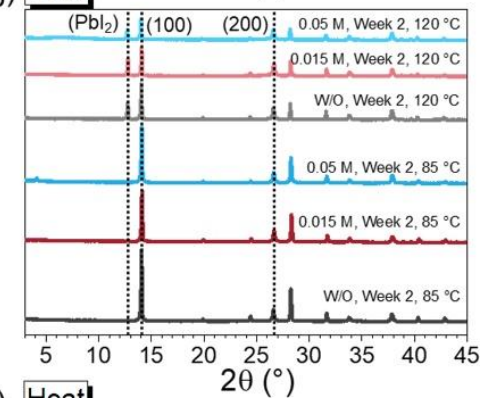

(j) Heat

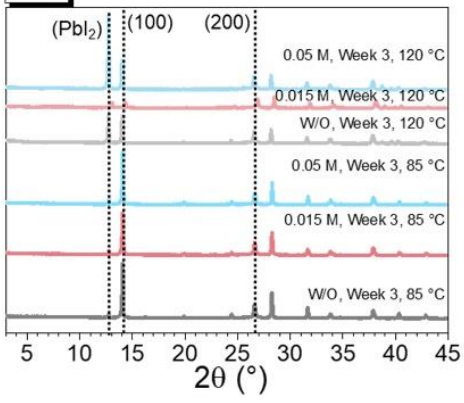

Figure S5. Stability testing of 3D/2D mixed $\mathrm{Pb} / \mathrm{Sn}$ perovskite films before and after PEAI posttreatment under a variety of environmental conditions. The XRD spectra of perovskite films with aging time of (a) 0 week, (b-d) 1 week, (e-g) 2 weeks, and (h-j) 3 weeks. 

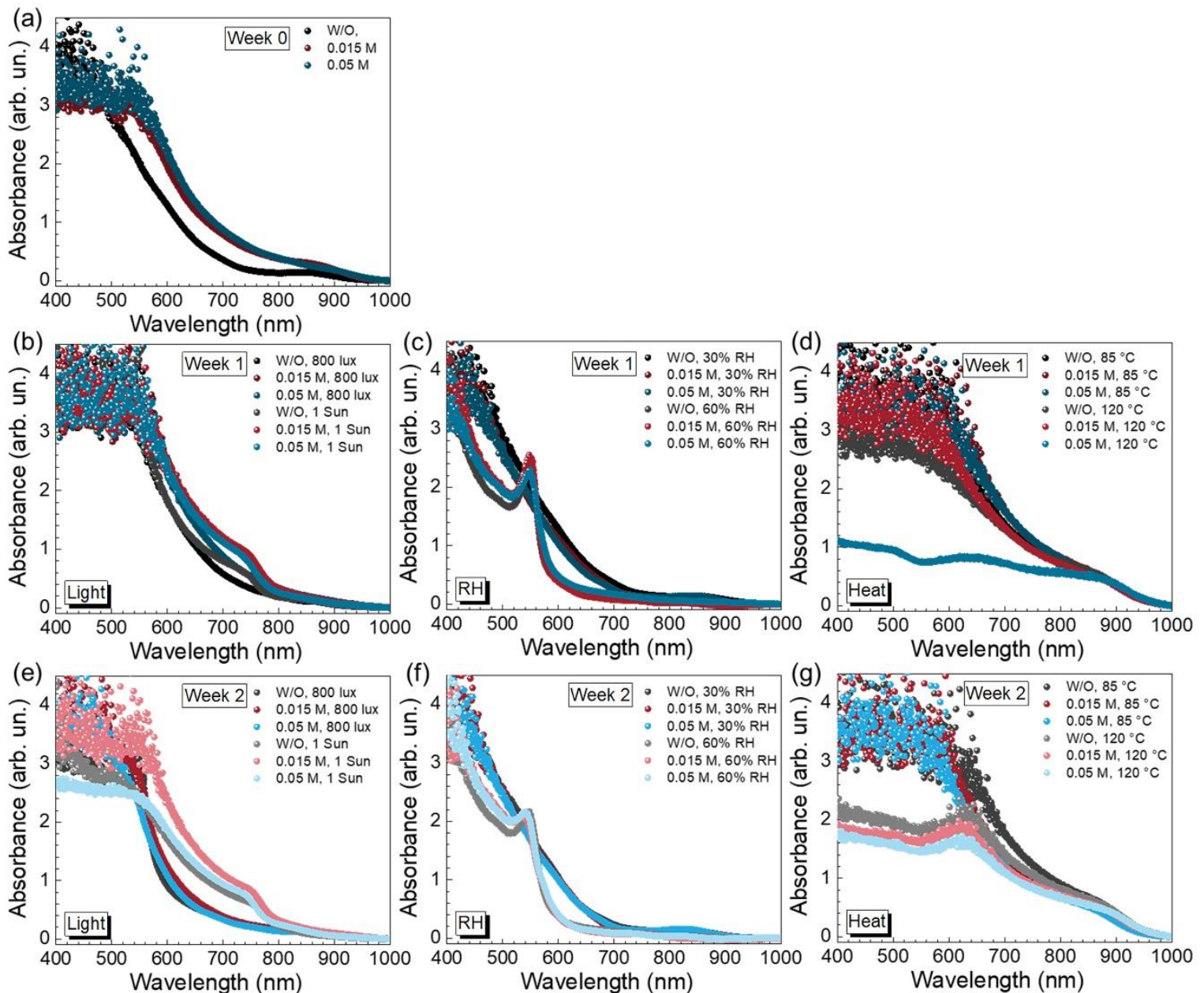

(h)

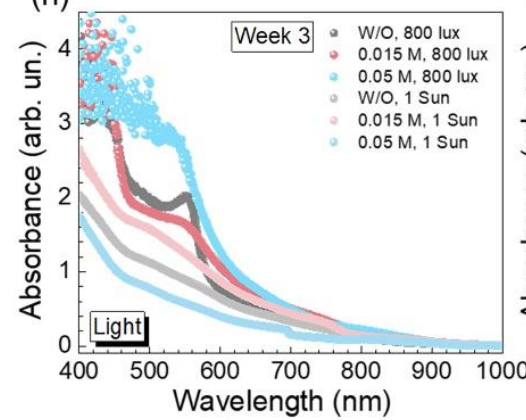

(i)

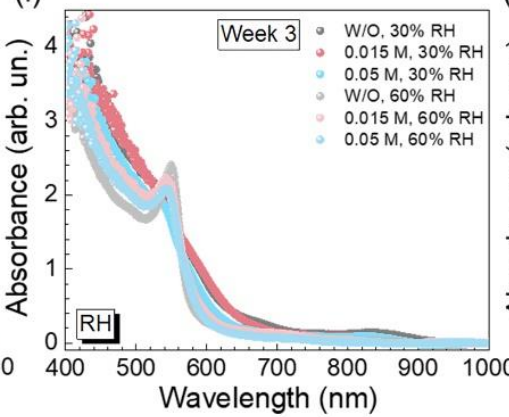

(j)

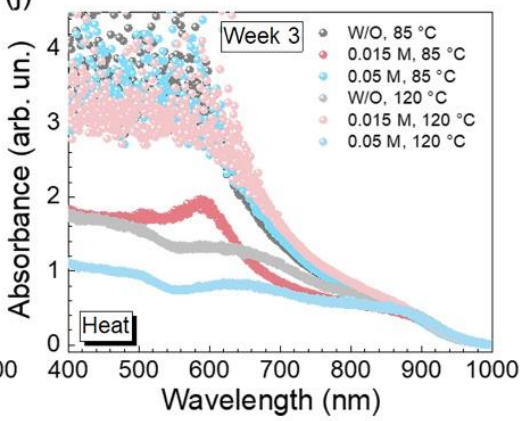

Figure S6. Stability testing of 3D/2D mixed $\mathrm{Pb} / \mathrm{Sn}$ perovskite films before and after PEAI posttreatment under a variety of environmental conditions. The absorption spectra of perovskite films with the aging time of (a) 0 week, (b-d) 1 week, (e-g) 2 weeks, and (h-j) 3 weeks. 


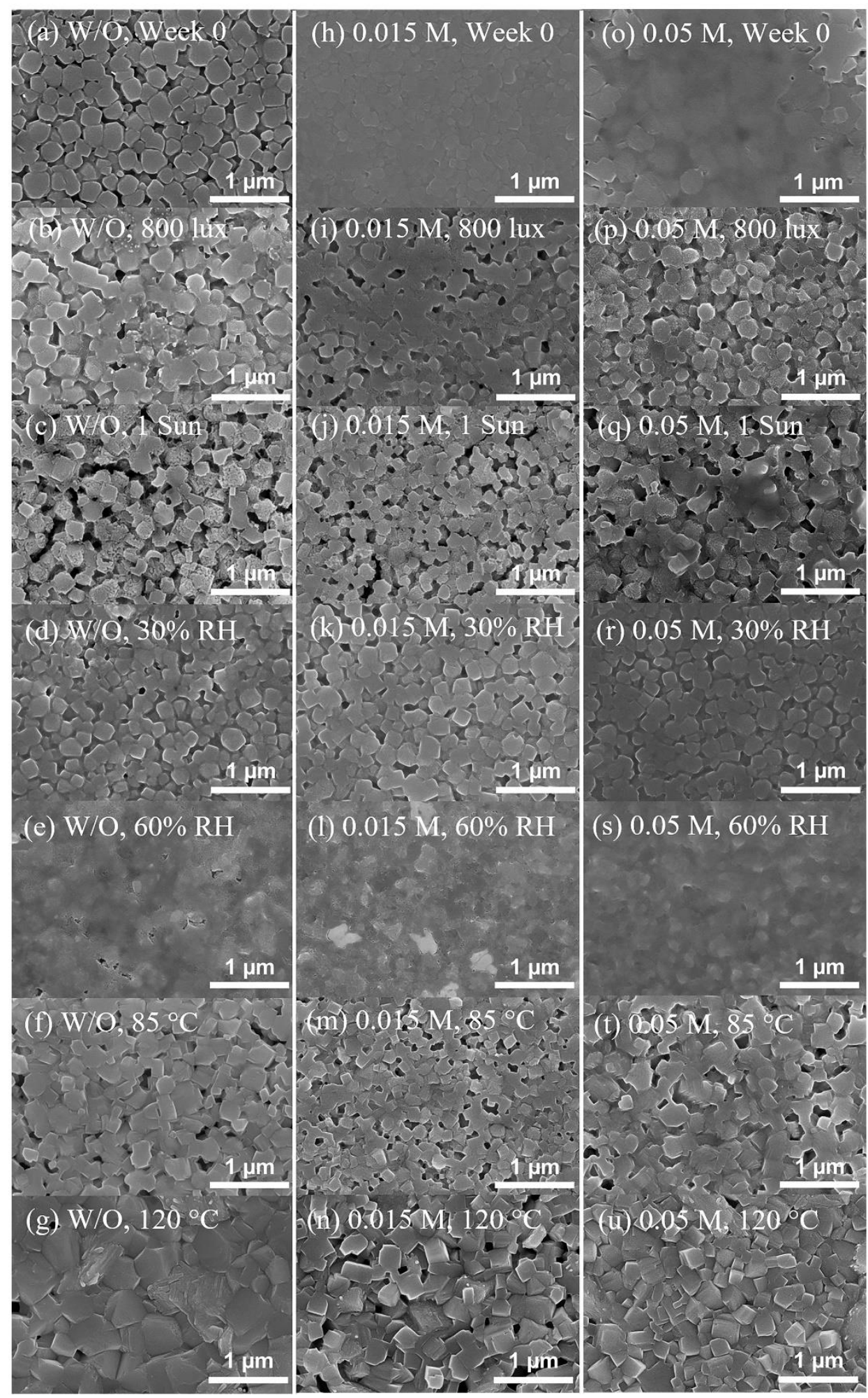

Figure S7. Stability testing of 3D/2D mixed $\mathrm{Pb} / \mathrm{Sn}$ perovskite films before and after PEAI posttreatment under a variety of environmental conditions. The surface morphologies of perovskite films with the aging time of 1 week. 


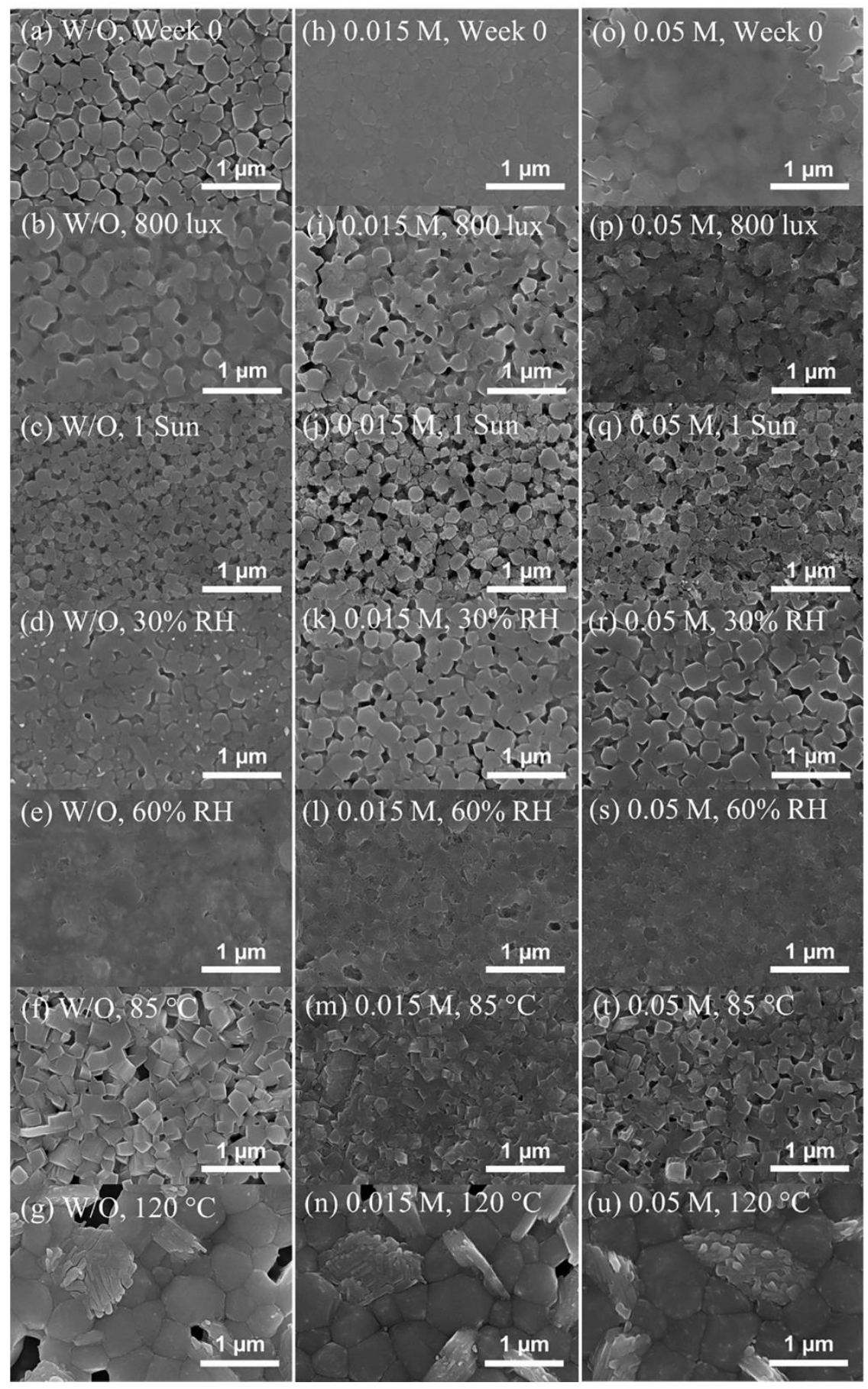

Figure S8. Stability testing of 3D/2D mixed $\mathrm{Pb} / \mathrm{Sn}$ perovskite films before and after PEAI posttreatment under a variety of environmental conditions. The surface morphologies of perovskite films with the aging time of 2 weeks. 


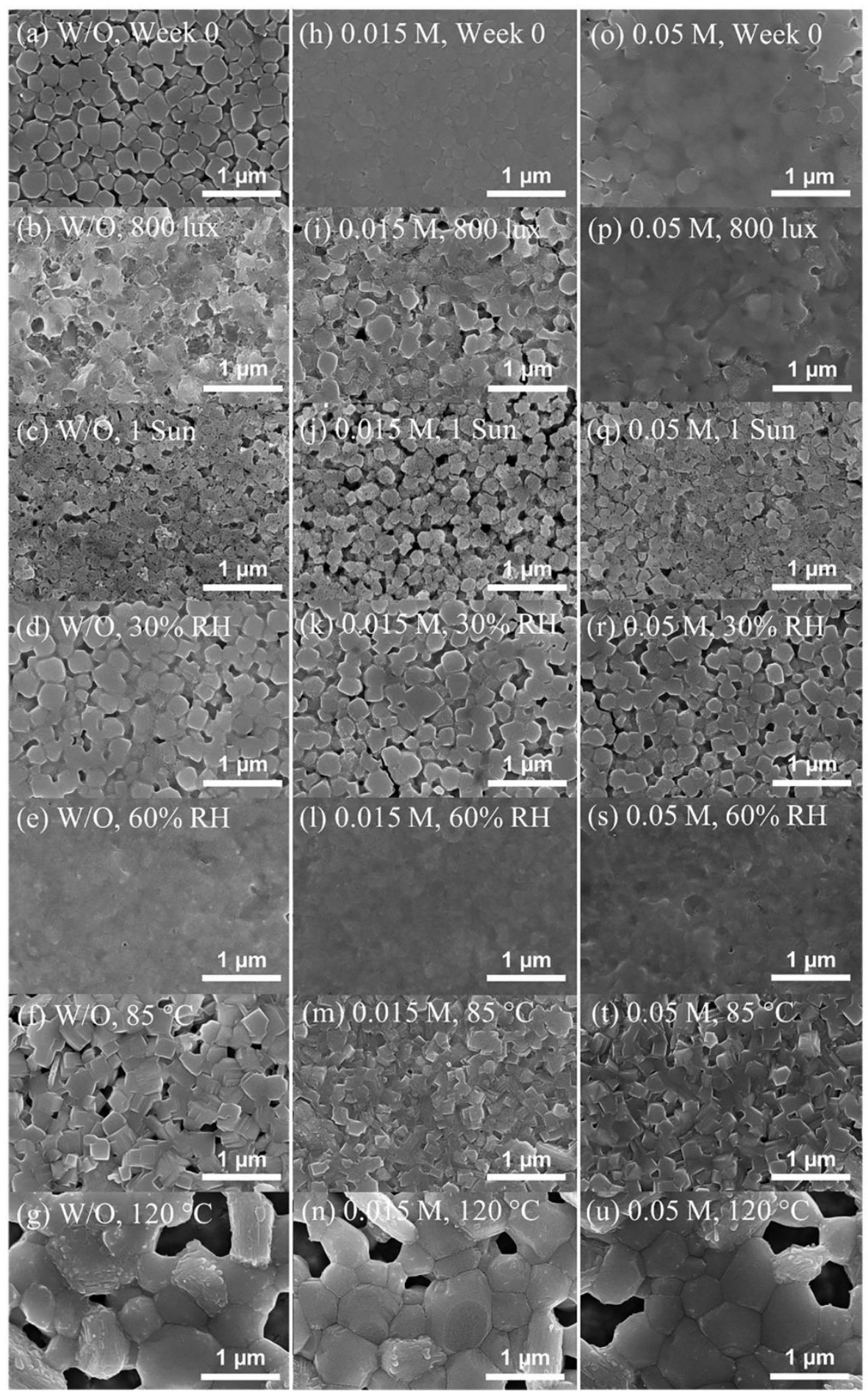

Figure S9. Stability testing of 3D/2D mixed $\mathrm{Pb} / \mathrm{Sn}$ perovskite films before and after PEAI posttreatment under a variety of environmental conditions. The surface morphologies of perovskite films with the aging time of 3 weeks. 


\section{References}

(1) Naikaew, A.; Kumnorkaew, P.; Supasai, T.; Suwanna, S.; Hunkao, R.; Srikhirin, T.; Kanjanaboos, P. Enhancing High Humidity Stability of Quasi-2D Perovskite Thin Films through Mixed Cation Doping and Solvent Engineering. ChemNanoMat 2019, 5, 12801288. https://doi.org/10.1002/cnma.201900189.

(2) Liang, H.; Yuan, F.; Johnston, A.; Gao, C.; Choubisa, H.; Gao, Y.; Wang, Y. K.; Sagar, L. K.; Sun, B.; Li, P. et. al. High Color Purity Lead-Free Perovskite Light-Emitting Diodes via Sn Stabilization. Adv. Sci. 2020, 7, 1903213. https://doi.org/10.1002/advs.201903213.

(3) Zhang, J.; Zhu, X.; Wang, M.; Hu, B. Establishing Charge-Transfer Excitons in 2D Perovskite Heterostructures. Nat. Commun. 2020, 11, 2618.

https://doi.org/10.1038/s41467-020-16415-1. 